\title{
PERAN BRAND IMAGE MEMEDIASI PENGARUH KUALITAS PRODUK TERHADAP LOYALITAS PELANGGAN
}

\section{Gusti Nyoman Bagus Dananjaya ${ }^{1}$ Ni Made Rastini²}

\author{
${ }^{1,2}$ Fakultas Ekonomi dan Bisnis Universitas Udayana (Unud), Bali, Indonesia \\ e-mail: akundananjaya@gmail.com
}

\begin{abstract}
ABSTRAK
Penelitian ini bertujuan untuk menjelaskan pengaruh kualitas produk terhadap brand image, pengaruh kualitas produk terhadap loyalitas pelanggan, pengaruh brand image terhadap loyalitas pelanggan, dan peran brand image memediasi pengaruh kualitas produk terhadap loyalitas pelanggan Kober Mie Setan di Kota Denpasar penelitian ini dilakukan di wilayah Kota Denpasar dengan menggunakan 100 responden. Metode pengumpulan data yang digunakan adalah metode purposive sampling dengan teknik analisis jalur. Hasil penelitian menunjukkan bahwa kualitas produk berpengaruh positif dan signifikan terhadap brand image. Kualitas produk berpengaruh positif dan signifikan terhadap loyalitas pelanggan. Brand image berpengaruh positif dan signifikan terhadap loyalitas pelanggan. Brand image sebagai variabel mediasi berpengaruh signifikan secara tidak langsung terhadap loyalitas pelanggan melalui variabel kualitas produk. Kober Mie Setan perlu memperhatikan porsi makanan agar sesuai dengan harapan konsumen. Selain itu, Kober Mie Setan perlu meningkatkan reputasi positif agar image Kober Mie Setan dinilai positif dan mampu menciptakan loyalitas pelanggan.
\end{abstract}

Kata kunci: kualitas produk, brand image, loyalitas pelanggan

\begin{abstract}
This research aims to explain the effect of product quality on brand image, the effect of product quality on customer loyalty, the influence of brand image on customer loyalty, and the role of brand image to mediate the effect of product quality on customer loyalty of Kober Mie Setan in Denpasar City This research was conducted in Denpasar using 100 respondents. Data collection method used is purposive sampling method with path analysis technique. The results showed that product quality had a positive and significant effect on brand image. Product quality has a positive and significant impact on customer loyalty. Brand image has a positive and significant impact on customer loyalty. Brand image as a mediation variable significantly indirect influence on customer loyalty through product quality variables. Kober Mie Satan needs to pay attention to the portion of food to match the expectations of the consumers. In addition, Kober Mie Satan needs to improve the positive reputation for the image of Kober Mie Satan is considered positive and able to create customer loyalty.
\end{abstract}

Keywords: product quality, brand image, customer loyalty 


\section{PENDAHULUAN}

Jenis usaha yang bisa dilakukan dalam berbisnis salah satunya yaitu bisnis kuliner. Bisnis kuliner dinilai menjanjikan karena produk dari bisnis kuliner adalah makanan dan minuman yang merupakan kebutuhan pokok. Industri kuliner di Indonesia saat ini mengalami perkembangan pesat sehingga menyebabkan persaingan semakin ketat. Oleh sebab itu, para pelaku bisnis kuliner dituntut mampu menerapkan strategi yang tepat untuk memenangi persaingan.

Salah satu pilihan kuliner yang digemari masyarakat adalah sebuah gerai makanan yang menyediakan menu makanan yang unik bagi pelanggannya, terutama makanan yang bercitarasa pedas Danghyang dkk. (2015). Saat ini mie telah berkembang menjadi salah satu makanan yang sangat diminati. Olahan mie saat ini tidak hanya sebatas mie ayam atau mie goreng seperti biasanya yang sudah umum di masyarakat. Melainkan mie bercitarasa pedas yang merupakan terobosan baru di bidang usaha kuliner. Itu merupakan salah satu bentuk kreativitas dan inovasi dari para pelaku bisnis kuliner.

Salah satu perusahaan penjual mie bercitarasa pedas adalah Kober Mie Setan yang berpusat di Kota Malang. Usaha yang berawal dari coba-coba atau sekedar mengisi waktu luang ini merupakan singkatan dari kelompok bermain yang artinya tempat berkumpulnya komunitas (komunitas otomotif di Kota Malang). Nama yang terbilang unik dan menyeramkan membuat masyarakat penasaran dan antusias untuk berkunjung ke tempat tersebut. Kober Mie Setan menawarkan produk makanan mie dengan berbagai macam tingkat level 
kepedasan yang bisa dipilih dan berbagai macam minuman yang tak kalah seram juga namanya (Ulfa dan Widodo, 2015).

Fenomena yang terjadi pada usaha Kober Mie Setan di Bali adalah tentang loyalitas pelanggan. Pada awal peluncuran cabang perdananya hingga saat ini telah memiliki enam cabang di Provinsi Bali, loyalitas pelanggan menjadi perhatian bagi peneliti. Hal ini dilihat dari pengamatan langsung peneliti bahwa antrian pesanan Kober Mie Setan di seluruh cabang sangatlah panjang. Antrian bahkan terjadi sebelum gerai Kober Mie Setan dibuka. Ini merupakan salah satu bentuk loyalitas pelanggan. Peneliti tertarik untuk meneliti fenomena ini karena loyalitas pelanggan tercipta sangat cepat pada Kober Mie Setan di Bali. Tidak seperti kompetitornya, loyalitas pelanggan Kober Mie Setan benar-benar terlihat jelas, dan nyata. Cabang Kober Mie Setan di Provinsi Bali terus bertambah menunjukkan permintaan konsumen terus meningkat dan adanya perilaku loyalitas pelanggan.

Hasil wawancara lisan yang peneliti lakukan pada konsumen Kober Mie Setan menyimpulkan bahwa sebagian besar konsumen loyal terhadap Kober Mie Setan karena mereka suka dari segi rasa, tampilan, variasi menu, dan suhu makanan. Mereka berpendapat bahwa menu makanan dan minuman di Kober Mie Setan tergolong unik dengan nama-nama menunya seperti Mie Iblis dan Mie Setan pada makanannya, Es Kuntilanak dan Es Genderuwo pada minumannya, Udang Rambutan, Siomay, Lumpia Udang pada dim sumnya, dan lain-lain. Mereka pun berpendapat bahwa Kober Mie Setan memiliki image yang positif 
sehingga berdampak pada pembelian ulang konsumen sekaligus menciptakan loyalitas pelanggan.

Berdasarkan latar belakang, maka rumusan masalah penelitian adalah sebagai berikut : 1) Bagaimana pengaruh kualitas produk terhadap brand image Kober Mie Setan di Kota Denpasar? 2) Bagaimana pengaruh kualitas produk terhadap loyalitas pelanggan Kober Mie Setan di Kota Denpasar? 3) Bagaimana pengaruh brand image terhadap loyalitas pelanggan Kober Mie Setan di kota Denpasar? 4) Bagaimana peran brand image memediasi pengaruh kualitas produk terhadap loyalitas pelanggan Kober Mie Setan di Kota Denpasar?

Berdasarkan rumusan masalah, maka tujuan dari penelitian ini adalah : 1) Untuk menjelaskan pengaruh kualitas produk terhadap brand image Kober Mie Setan di Kota Denpasar 2) Untuk menjelaskan pengaruh kualitas produk terhadap loyalitas pelanggan Kober Mie Setan di Kota Denpasar 3) Untuk menjelaskan pengaruh brand image terhadap loyalitas pelanggan Kober Mie Setan di kota Denpasar. 4) Untuk menjelaskan peran brand image memediasi pengaruh kualitas produk terhadap loyalitas pelanggan Kober Mie Setan di Kota Denpasar.

Berdasarkan tujuan penelitian yang telah diuraikan, adapun kegunaan dari penelitian ini adalah : 1) Kegunaan Teoritis dari penelitian ini diharapkan dapat memberikan tambahan pengetahuan, wawasan dan informasi mengenai peran brand image memediasi pengaruh kualitas produk terhadap loyalitas pelanggan Kober Mie Setan di Kota Denpasar, serta dapat menjadi refrensi bagi penelitian berikutnya. 2) Kegunaan Praktis dari hasil penelitian ini diharapkan dapat memberikan informasi kepada para pemasar mengenai peran brand image, 
kualitas produk terhadap loyalitas pelanggan Kober Mie Setan di Kota Denpasar agar para pemasar lebih meningkatkan kualitas produk agar menghasilkan brand image positif yang akan berpengaruh pada loyalitas pelanggan.

Tjiptono (2014:298) berpendapat kualitas merupakan perpaduan antara sifat dan karakteristik yang menentukan sejauh mana dapat memenuhi prasyarat kebutuhan pelanggan atau menilai sampai seberapa jauh sifat dan karakteristik itu memenuhi kebutuhannya. Irwanty (2017), Noerchoidah (2013), dan Saraswati dan Rahyuda (2017) menyatakan bahwa kualitas produk memiliki pengaruh yang positif terhadap brand image. Berdasarkan teori dan penelitian sebelumnya maka dapat dirumuskan hipotesis sebagai berikut:

$\mathrm{H}_{1}$ : Kualitas produk berpengaruh positif dan signifikan terhadap brand image

Penelitian yang dilakukan oleh Amryyanti et al. (2013), Minar dan Safitri (2017), serta Halim et al. (2014) menyatakan bahwa terdapat pengaruh positif dan signifikan antara kualitas produk dengan loyalitas pelanggan. Berdasarkan teori dan penelitian sebelumnya maka dapat dirumuskan hipotesis sebagai berikut:

$\mathrm{H}_{2}$ : Kualitas produk berpengaruh positif dan signifikan terhadap loyalitas pelanggan.

Kotler dan Amstrong (2016:225) menjelaskan brand image (citra merek) adalah seperangkat keyakinan konsumen mengenai merek tertentu. Ini mengacu pada kumpulan asosiasi yang terkait dengan merek yang dikembangkan di benak pelanggan. Tjahjaningsih (2013), Liao (2012), Chao et al. (2015) dan Sulibhavi (2017) menyatakan bahwa terdapat pengaruh positif dan signifikan antara brand image dengan loyalitas pelanggan. Berdasarkan teori dan penelitian sebelumnya maka dapat dirumuskan hipotesis sebagai berikut: 
$\mathrm{H}_{3}$ : Brand image berpengaruh positif dan signifikan terhadap loyalitas pelanggan.

Pi dan Huang (2011) menunjukkan bahwa loyalitas pelanggan dapat diperlihatkan melalui sikap dan perilaku. Sikap termasuk niat pembelian kembali atau membeli produk lain dari perusahaan, niat untuk merekomendasikan dan kekebalan terhadap pesaing. Griffin (2005:31) dalam Kurniawati (2014) pelanggan yang loyal adalah orang yang melakukan pembelian ulang secara teratur, membeli antar lini produk barang dan jasa, mereferensikan pada orang lain, dan kebal terhadap produk pesaing. Penelitian yang dilakukan oleh Pertiwi dan Sukawati (2017), Dei dan Sukaatmaja (2015), Purnamasari dan Murwatiningsih (2015), serta Gill dan Dawra (2010) menyatakan bahwa brand image mampu memediasi secara positif dan signifikan terhadap suatu variabel. Berdasarkan teori dan penelitian sebelumnya maka dapat dirumuskan hipotesis sebagai berikut:

$\mathrm{H}_{4}$ : Brand image berpengaruh positif signifikan dalam memediasi kualitas produk dengan loyalitas pelanggan

Berdasarkan hipotesis yang telah diuraikan sebelumnya, maka dapat digambarkan kerangka konseptual sebagai berikut:

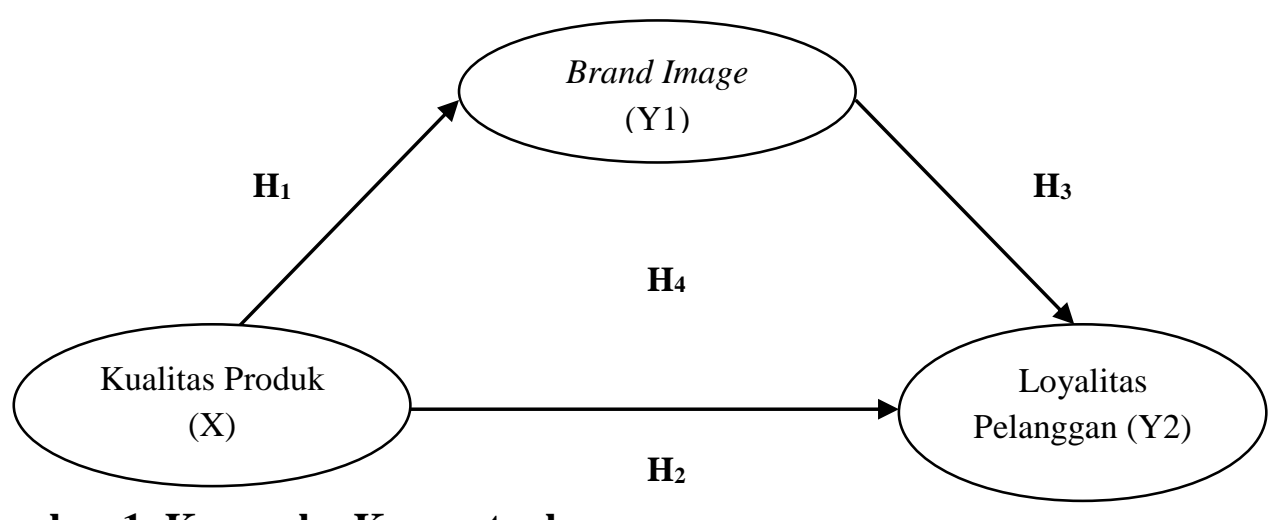

\section{Gambar 1. Kerangka Konseptual}




\section{METODE PENELITIAN}

Penelitian ini menggunakan pendekatan kuantitatif yang berbentuk asosiatif, karena bertujuan untuk mengetahui hubungan dua variabel atau lebih (Sugiyono, 2013:55) yaitu variabel bebas kualitas produk (X) dengan satu variabel terikat yaitu loyaltas pelanggan (Y2) dengan variabel mediasi yaitu brand image (Y1). wilayah Kota Denpasar. Lokasi ini dipilih karena sebagian besar cabang Kober Mie Setan di Provinsi Bali ada di Kota Denpasar sekaligus merupakan ibukota Provinsi Bali dengan penduduk yang padat serta tingginya kebutuhan primer seperti makanan dan minuman. Sehingga memungkinkan peneliti menemukan konsumen dengan perilaku yang cenderung loyal terhadap Kober Mie Setan.

Variabel Endogen pada penelitian ini adalah loyalitas pelanggan (Y2). Variabel Intervening pada penelitian ini adalah brand image (Y1) dan Variabel Eksogen dalam penelitian ini adalah kualitas produk (X)

Populasi dalam penelitian ini adalah konsumen Kober Mie Setan di wilayah Denpasar. Populasi dalam penelitian ini bersifat infinite (tidak terbatas). Teknik penentuan sampel yang digunakan pada penelitian ini adalah non probability sampling dengan metode purposive sampling, yaitu sampel ditentukan dengan pertimbangan tertentu. Kriteria sampel dalam penelitian ini adalah: 1) Berdomisili di Kota Denpasar. Pertimbangan pemilihan di kota Denpasar karena penelitian ini dilakukan pada masyarakat kota Denpasar sehingga data akan lebih valid jika responden merupakan domisili Denpasar. 2) Pendidikan terakhir minimal 
SMA/SMK sederajat. Pertimbangan ini digunakan dengan alasan seseorang dengan jenjang pendidikan minimal SMA/SMK dapat memahami isi dari kuesioner. 3) Responden yang loyal terhadap Kober Mie Setan dengan melakukan pembelian secara intensif dalam 2 bulan terakhir dan merekomendasikannya kepada orang lain.Sumber data yang digunakan adalah data sekunder. Sekaran (2014:85) mengemukakan ukuran sampel yang baik adalah 5 - 10 kali jumlah variabel atau indikator dalam penelitian. Penelitian ini menggunakan 10 indikator sehingga dengan menggunakan estimasi berdasarkan jumlah parameter diperoleh ukuran sampel sebesar $50-100$ responden. Jadi, dengan dipilihnya 100 responden artinya sudah sesuai dengan kriteria yang ditentukan. Jenis data berdasarkan sifat dalam penelitian ini adalah data kuantitatif yaitu pengambilan sampel sebanyak 100 responden berdasarkan kuisioner yang akan disebarkan, data kualitatif, yaitu dengan melakukan wawancara secara langsung kepada konsumen yang berada di Kota Denpasar untuk mendapat penilaian tentang baik atau tidaknya kualitas produk dan brand image yang dikatakan secara langsung maupun tidak langsung oleh konsumen. Jenis data berdasarkan sumber dalam penelitian ini adalah data primer yaitu data langsung yang diperoleh dari lokasi penelitian yaitu di wilayah Kota Denpasar yang berupa hasil penyebaran kuesioner dan data sekunder yaitu data yang bukan diperoleh secara langsung oleh peneliti, melainkan dilakukan oleh pihak lain atau lembaga tertentu. Data yang dimaksud seperti hasil penelitian dari jurnal peneliti lain. Instrumen penelitian ini adalah berupa kuesioner.

Penelitian ini menggunakan teknik analisis jalur (path analysis). Teknik analisis jalur ini dapat didefinisikan sebagai perluasan dari analisis linier berganda 
Gusti Nyoman Bagus Dananjaya, Peran Brand Image Memediasi...

dalam memperkirakan hubungan kausalitas antara yang telah ditetapkan berdasarkan teori. Analisis jalur digunakan untuk menentukan hubungan 3 variabel atau lebih dalam mengkorfimasi dan menolak hipotesis (Ghozali, 2011:249). Analisis jalur digunakan untuk menganalisis pola hubungan antar variabel dengan tujuan untuk mengetahui pengaruh langsung maupun tidak langsung variabel eksogen terhadap variabel endogen. Dasar perhitungan koefisian jalur adalah analisis korelasi dan regresi dan dalam perhitungannya menggunakan software dengan program SPSS for windows.

Adapun langkah-langkah dalam menguji hipotesis penelitian yang telah disusun dengan menggunakan path analysis menurut Riduwan dan Kuncoro (2011:152) adalah berdasarkan model penelitian maka diagram jalur dalam penelitian ini dapat disajikan sebagai berikut:

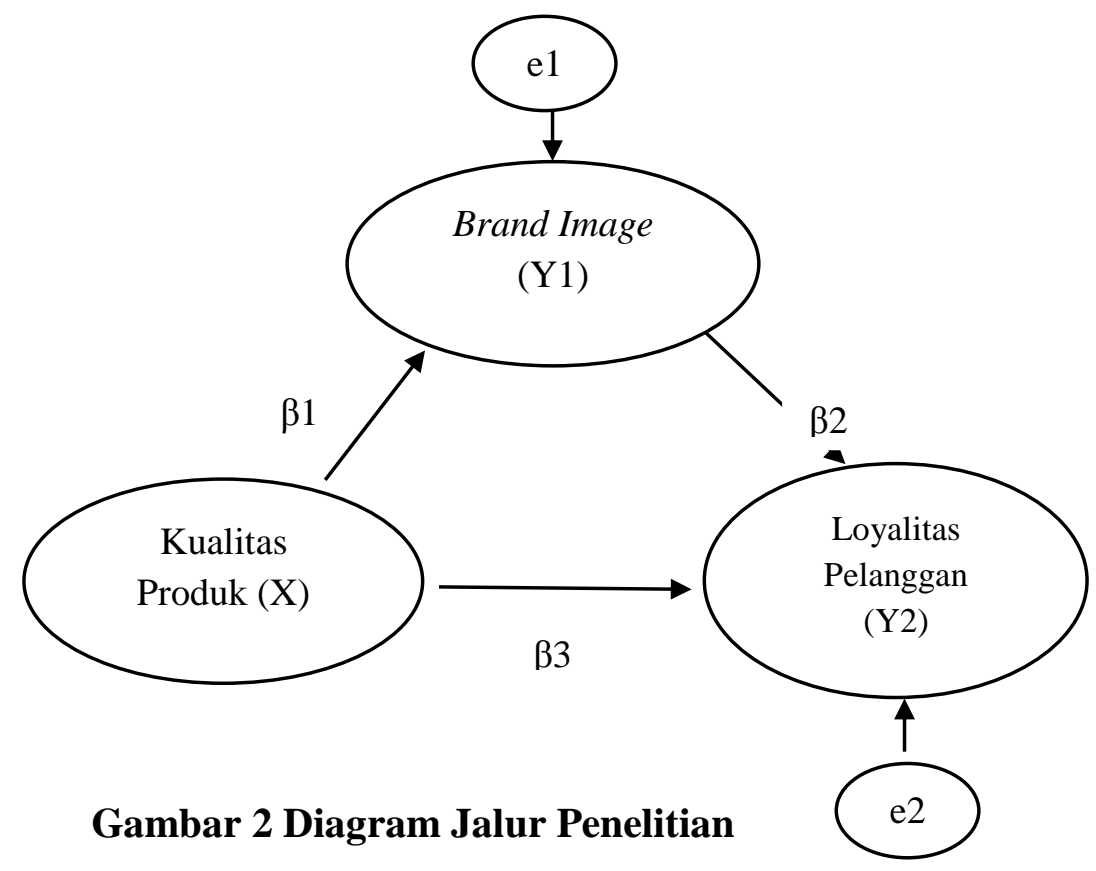


Keterangan:

$$
\begin{array}{ll}
\mathrm{X} & =\text { variabel eksogen/dependen Kualitas Produk } \\
\mathrm{Y} 1 & =\text { variabel mediasi Brand image } \\
\mathrm{Y} 2 & =\text { variabel endogen/independen Loyalitas Pelanggan } \\
\beta 1, \beta 2, \beta 3 & =\text { koefisien regresi } \\
\mathrm{e}, \mathrm{e} 2 & =\text { nilai kekeliruan taksiran standar }
\end{array}
$$

Berdasarkan diagram jalur yang telah disusun, persamaan struktural dalam penelitian ini dapat dilihat sebagai berikut:

Persamaan substruktur I

$\mathrm{Y} 1=\mathrm{B}_{1} \mathrm{X}+\mathrm{e} 1$

Keterangan:

$\mathrm{B}_{1}=$ koefisien jalur dari Kualitas Produk

$\mathrm{X}=$ Kualitas Produk

$\mathrm{Y} 1$ = Brand Image

e1 = nilai kekeliruan taksiran standar

Persamaan substuktural 2

$\mathrm{Y}=\mathrm{B}_{2} \mathrm{M}+\mathrm{B}_{3} \mathrm{X}+\mathrm{e} 2$

Keterangan:

Y2 = Loyalitas Pelanggan

$\mathrm{B}_{2}=$ koefisien jalur dari Brand Image

$\mathrm{B}_{3}=$ koefisien jalur dari Kualitas Produk

$\mathrm{X}=$ Kualitas Produk

$\mathrm{Y} 1$ = Brand Image

e2 = nilai kekeliruan taksiran standar 
3) Menghitung Nilai Koefisien Determinasi $\left(\mathrm{R}^{2}\right)$ dan Varian Error (e)

Koefisien determinasi $\left(\mathrm{R}^{2}\right)$ digunakan untuk mengukur besarnya kontribusi variabel eksogen (kualitas produk dan brand image) terhadap variabel endogen (loyalitas pelanggan) secara gabungan dan juga untuk mengetahui ketepatan alat analisis data. Total keragaman data yang dapat dijelaskan oleh model diukur dengan:

$\mathrm{R}_{\mathrm{m}}^{2}=1-\left(\mathrm{Pe}_{1}\right)^{2}\left(\mathrm{Pe}_{2}\right)^{2}$

Variabel error (e) merupakan kumpulan variabel eksogen lainnya yang tidak dimasukkan dalam sistem penelitian yang dimungkinkan masih mempengaruhi variabel terikat. Untuk menghitung nilai variabel error (e) dapat dihitung dengan menggunakan rumus sebagai berikut (Sarwono, 2012:78).

$\mathrm{Pe}_{\mathrm{i}}=\sqrt{1-R^{2}}$

4) Menghitung pengaruh langsung

a) Pengaruh variabel kualitas produk (X) terhadap brand image (Y1)

b) Pengaruh variabel kualitas produk $(\mathrm{X})$ terhadap loyalitas pelanggan (Y2)

c) Pengaruh brand image (Y1) terhadap loyalitas pelanggan (Y2)

5) Menghitung pengaruh tidak langsung variabel kualitas produk (X) terhadap loyalitas pelanggan (Y2) dengan brand image (Y1) sebagai variabel mediasi.

6) Uji mediasi (uji sobel)

Uji sobel merupakan alat analisis untuk menguji signifikansi dari hubungan tidak langsung antara variabel independen dengan variabel dependen yang dimediasi oleh variabel mediator.. Berdasarkan pengujian ini dapat diteliti 
tingkat intervensi dari variabel mediasi apakah memediasi penuh atau memediasi sebagian atau bukan mediasi. Metode pengujian variabel mediasi yang digunakan adalah sebagai berikut (Hair et al.., 2010) dalam Pratama (2018):

a) Memeriksa pengaruh langsung variabel independen terhadap variabel dependen pada model dengan melibatkan variabel mediasi.

b) Memeriksa pengaruh variabel independen terhadap variabel dependen pada model tanpa melibatkan variabel mediasi.

c) Memeriksa pengaruh variabel independen terhadap variabel mediasi.

d) Memeriksa pengaruh variabel mediasi terhadap variabel dependen.

Berdasarkan hasil investigasi keempat pengaruh tersebut $(1,2,3$, dan 4), maka selanjutnya dapat ditentukan tingkat intervensi dari variabel mediasi dengan tahap-tahap analisis sebagai berikut:

a) Jika pengaruh variabel independen terhadap variabel mediasi (3) adalah signifikan, pengaruh variabel mediasi terhadap variabel dependen (4) adalah signifikan, pengaruh langsung variabel independen terhadap variabel dependen pada model dengan melibatkan variabel mediasi (1) non signifikan, pengaruh langsung variabel independen terhadap variabel dependen tanpa melibatkan variabel mediasi (2) adalah signifikan, maka dikatakan sebagai variabel mediasi sempurna (complete/full mediation).

b) Jika pengaruh variabel independen terhadap variabel mediasi (3) adalah signifikan, pengaruh variabel mediasi terhadap variabel dependen (4) adalah signifikan, pengaruh langsung variabel independen terhadap 
Gusti Nyoman Bagus Dananjaya, Peran Brand Image Memediasi...

variabel dependen pada model dengan melibatkan variabel mediasi (1) adalah signifikan, dan pengarh langsung variabel independen terhadap variabel dependen tanpa melibatkan variabel mediassi (2) adalah signifikan, maka dikatakan sebagai variabel mediasi sebagian (partial mediation).

c) Jika pada (3), (4) signifikan dan pada (1) signifikan, di mana koefisien dari (1) hampir sama dengan (2) maka dikatakan bukan sebagai variabel mediasi.

d) Jika salah satu (3) atau (4) nonsignifikan maka dikatakan bukan sebagai variabel mediasi.

Uji Sobel dirumuskan dengan persamaan berikut dan dapat dihitung dengan menggunakan aplikasi Microsoft Excel 2007. Bila nilai kalkulasi Z lebih besar dari 1,98 (dengan tingkat kepercayaan 95 persen), maka variabel mediator dinilai secara signifikan memediasi hubungan antara variabel terikat dan variabel bebas.

Uji Sobel dapat dirumuskan ke dalam rumus sebagai berikut:

$$
\mathrm{Sab}=\sqrt{b^{2} s a^{2}+a^{2} s b^{2}+s a^{2} s b^{2}}
$$

\section{Keterangan:}

$\mathrm{S}_{\mathrm{ab}} \quad=$ besarnya standard error tidak langsung

$\mathrm{S}_{\mathrm{a}}=$ standard error koefisien $\mathrm{a}$

$\mathrm{S}_{\mathrm{b}}=$ standard error koefisien $\mathrm{b}$

$\mathrm{a} \quad=$ koefisien jalur $\mathrm{X}$ terhadap $\mathrm{Y} 1$ 


$$
\begin{aligned}
\mathrm{b}= & \text { koefisien jalur } \mathrm{Y} 1 \text { terhadap } \mathrm{Y} 2 \\
\mathrm{ab}= & \text { hasil kali koefisien jalur } \mathrm{X} \text { terhadap koefisien jalur } \mathrm{Y} 1 \text { (a) dengan } \\
& \text { jalur } \mathrm{Y} 1 \text { terhadap } \mathrm{Y} 2 \text { (b). }
\end{aligned}
$$

\section{HASIL DAN PEMBAHASAN}

Responden penelitian digambarkan secara umum dengan menyajikan karakteristiknya dilihat dari beberapa variabel demografi yaitu jenis kelamin, usia, pekerjaan, pendidikan yang diselesaikan, serta penghasilan atau uang saku responden yang disajikan dalam Tabel 1 .

Berdasarkan Tabel 1. dapat dilihat dari jenis kelamin perempuan mendominasi dalam responden yang peneliti lakukan yaitu sebanyak 55 persen dan laki-laki 45 persen. Menurut pengelompokan usia, mayoritas responden berusia 19 - 21 tahun sebanyak 60 persen, lalu responden berusia 22-26 tahun sebanyak 40 persen. Dilihat dari pekerjaan responden 91 persen merupakan mahasiswa, 3 persen responden merupakan pengusaha, dan 2 persen pekerjaan lainnya. Dilihat dari pendidikan yang diselesaikan responden, SMA/Sederajat sebesar 72 persen, S1 sebesar 25 persen, Diploma sebesar 2 persen, dan S2 sebesar 1 persen. Dilihat dari penghasilan atau uang saku responden. Rp 1.000.000 - Rp 2.499.999 sebesar 76 persen dan Rp 2.500.000 - Rp 3.499.999 sebesar 24 persen

Suatu kuesioner dikatakan valid jika pernyataan pada kuesioner mampu untuk mengungkapkan sesuatu yang diukur oleh kuesioner tersebut. Hasil uji validitas instrumen penelitian akan disajikan pada Tabel 2 
Tabel 1.

Karakteristik Responden

\begin{tabular}{|c|c|c|c|c|c|}
\hline No & Variabel & Klasifikasi & & Jumlah & $\begin{array}{c}\text { Persen } \\
(\%)\end{array}$ \\
\hline \multirow[t]{3}{*}{1} & Jenis Kelamin & Laki-laki & & 45 & 45 \\
\hline & & Perempuan & & 55 & 55 \\
\hline & & & Total & 100 & 100 \\
\hline \multirow[t]{6}{*}{2} & Usia & 19-24 tahun & & 60 & 60 \\
\hline & & $22-26$ tahun & & 40 & 40 \\
\hline & & 27-31 tahun & & 0 & 0 \\
\hline & & 32-36 tahun & & 0 & 0 \\
\hline & & diatas 42 tahun & & 0 & 0 \\
\hline & & & Total & 100 & 100 \\
\hline \multirow[t]{6}{*}{3} & Pekerjaan & Mahasiswa & & 91 & 91 \\
\hline & & Pengusaha & & 3 & 3 \\
\hline & & PNS & & 0 & 0 \\
\hline & & Karyawan Swasta & & 4 & 4 \\
\hline & & Lain-lain & & 2 & 2 \\
\hline & & & Total & 100 & 100 \\
\hline \multirow[t]{6}{*}{4} & Pendidikan & SMA/Sederajat & & 72 & 72 \\
\hline & yang & Diploma & & 2 & 2 \\
\hline & diselesaikan & $\mathrm{S} 1$ & & 25 & 25 \\
\hline & & S2 & & 1 & 1 \\
\hline & & S3 & & 0 & 0 \\
\hline & & & Total & 100 & 100 \\
\hline \multirow[t]{5}{*}{5} & Penghasilan & Kurang dari Rp. 1.000 .000 & & 0 & 0 \\
\hline & atau uang saku & Rp 1.000.000 - Rp 2.499.999 & & 76 & 76 \\
\hline & & Rp 2.500.000 - Rp 3.499.999 & & 24 & 24 \\
\hline & & Lebih dari Rp 3.500.000 & & 0 & 0 \\
\hline & & & Total & 100 & 100 \\
\hline
\end{tabular}

Sumber: Data primer diolah, 2018 
Tabel 2

Hasil Uji Validitas

\begin{tabular}{cccc}
\hline Variabel & Instrumen & Pearson Correlation & Keterangan \\
\hline Kualitas Produk & X1.1 & 0,731 & Valid \\
(X1) & X1.2 & 0,731 & Valid \\
& X1.3 & 0,734 & Valid \\
Brand Image & Y1.4 & 0,820 & Valid \\
(Y1) & Y1.2 & 0,800 & Valid \\
& Y1.3 & 0,861 & Valid \\
Loyalitas & Y2.1 & 0,882 & Valid \\
Pelanggan & Y2.2 & 0,850 & Valid \\
(Y2) & Y2.3 & 0,884 & Valid \\
\hline
\end{tabular}

Sumber : Data primer diolah, 2018

Tabel 2 menunjukkan variabel kualitas produk memiliki pearson correlation dari $0,731-0,820(>0,30)$, hal ini berarti bahwa pernyataan tersebut valid. Variabel brand image memiliki pearson correlation dari 0,800 - 0,882 (> 0,30), hal ini berarti bahwa pernyataan dalam kuesioner adalah valid. Variabel loyalitas pelanggan memiliki pearson correlation $0,850-0,884(>0,30)$, hal ini berarti bahwa pernyataan tersebut juga valid.

Pengujian reliabilitas dalam penelitian ini menggunakan metode Cronbach's Alpha. Instrumen dikatakan reliable untuk mengukur variabel bila berada di atas angka 0,60. Hasil pengujian reliabilitas instrument dapat dilihat pada Tabel 3

Tabel 3

Hasil Uji Reliabilitas

\begin{tabular}{ccc}
\hline Variabel & Cronbach's Alpha & Keterangan \\
\hline Kualitas Produk & 0,785 & Reliabel \\
Brand Image & 0,673 & Reliabel \\
Loyalitas Pelanggan & 0,781 & Reliabel \\
\hline Sumber : data primer diolah, 2018 & &
\end{tabular}


Berdasarkan Tabel 3 dapat dilihat bahwa nilai alpha dihitung masingmasing variabel lebih besar dari Cronbach's Alpha tabel yaitu 0,60 sehingga dapat disimpulkan bahwa pernyataan dalam kuesioner tersebut reliabel.

Pengujian persamaan 1 dilakukan untuk melihat pengaruh Brand Image terhadap Kualitas Produk yang dilakukan dengan menggunakan program SPSS. Berdasarkan hasil olah data, maka hasil uji regresi dapat disajikan dalam Tabel 4

Tabel 4.

Hasil Uji Regresi Pengaruh Kualitas Produk terhadap Brand Image

\begin{tabular}{|c|c|c|c|c|c|c|}
\hline \multirow{2}{*}{\multicolumn{2}{|c|}{ Model }} & \multicolumn{2}{|c|}{ Unstandardized Coefficients } & \multirow{2}{*}{$\begin{array}{c}\text { Standardized Coefficients } \\
\text { Beta }\end{array}$} & \multirow[t]{2}{*}{$\mathbf{t}$} & \multirow[t]{2}{*}{ Sig. } \\
\hline & & B & Std. Error & & & \\
\hline \multirow{2}{*}{1} & (Constant) & 2.497 & 1.191 & & 2.096 & .039 \\
\hline & Kualitas_Produk & .585 & .074 & .624 & 7.904 & .000 \\
\hline
\end{tabular}

Sumber : data primer diolah, 2018

Tabel 4 Menunjukan hasil uji regresi pengaruh kualitas produk terhadap brand image dengan nilai Sig. 0,000 $<0,05$ menunjukkan bahwa kualitas produk berpengaruh positif dan signifikan berhadap terhadap brand image.

Pengujian persamaan 2 dilakukan untuk melihat pengaruh kualitas produk dan brand image terhadap loyalitas pelanggan yang dilakukan dengan menggunakan program SPSS. Hasil uji regresi dapat disajikan dalam Tabel 5 berikut:

Tabel 5.

Hasil Uji Regresi Brand Image dan Kualitas Produk terhadap Loyalitas

Pelanggan

\begin{tabular}{lcccccc}
\hline Model & \multicolumn{2}{c}{ Unstandardized Coefficients } & Standardized Coefficients & t & Sig. \\
& B & Std. Error & Beta & & & \\
\hline (Constant) & -.462 & .913 & & -.506 & .614 \\
1 Kualitas_Produk & .397 & .071 & .425 & 5.588 & .000 \\
\multicolumn{1}{c}{ Brand_Image } & .473 & .076 & .475 & 6.250 & .000 \\
\hline Sumber $:$ Data diolah, 2018 & & & & &
\end{tabular}


Tabel 5 menunjukan hasil uji regresi pengaruh brand image dan kualitas produk terhadap loyalitas pelanggan. Kualitas produk dengan nilai Sig. $0,000<$ 0,05 menunjukan bahwa kualitas produk berpengaruh positif dan signifikan terhadap loyalitas pelanggan. Brand image dengan nilai Sig. 0,000 $<0,05$ menunjukan bahwa brand image berpengaruh positif dan signifikan terhadap loyalitas pelanggan.

Berdasarkan hasil olah data pada tabel 4 dan Tabel 5, maka dapat dibuat hubungan-hubungan antar variabel penelitian yang merupakan koefisien jalur dalam penelitian ini. Koefisien jalur dapat dibuat dalam bentuk diagram jalur. Model tersebut juga dapat dinyatakan dalam persamaan struktural, yaitu

$\mathrm{Y} 1=0,624 \mathrm{~B}_{1} \mathrm{X}$

$\mathrm{Y} 2=0,475 \mathrm{~B}_{2} \mathrm{Y} 1+0,425 \mathrm{~B}_{3} \mathrm{X}$

Tabel 6 menjelaskan bahwa variabel Kualitas Produk (X) berpengaruh signifikan terhadap Brand Image (Y1), Variabel Brand Image (Y1) berpengaruh signifikan terhadap Loyalitas Pelanggan (Y2), dan Variabel Kualitas Produk (X) berpengaruh signifikan terhadap Loyalitas Pelanggan (Y2).

Untuk mengetahui nilai $\mathrm{e}_{1}$ yang menunjukkan jumlah variance variabel brand image yang tidak dijelaskan oleh variabel kualitas produk dihitung menggunakan rumus.

$$
\begin{aligned}
\mathrm{e}_{\mathrm{i}} & =\sqrt{1-R^{2}} \ldots \ldots \\
& =\sqrt{1-0,389} \\
& =0,782
\end{aligned}
$$


Nilai variance variabel brand image yang tidak dijelaskan oleh variabel kualitas produk sebesar 0,782 berarti terdapat kumpulan variabel eksogen lainnya yang tidak dimasukkan dalam sistem penelitian yang dimungkinkan masih mempengaruhi variabel endogen atau loyalitas pelanggan (Y2).

Untuk mengetahui nilai $e_{2}$ yang menunjukkan variance variabel loyalitas pelanggan yang tidak dijelaskan oleh variabel kualitas produk dan brand image, maka dihitung menggunakan rumus.

$$
\begin{aligned}
e_{2} & =\sqrt{1-R^{2}} \ldots \ldots \\
& =\sqrt{1-0,658} \\
& =0,585
\end{aligned}
$$

Nilai variance variabel loyalitas pelanggan yang tidak dijelaskan oleh variabel kualitas produk dan brand image sebesar 0,585 berarti terdapat kumpulan variabel eksogen lainnya tidak dimasukkan dalam penelitian ini yang mungkin masih dapat mempengaruhi variabel endogen atau loyalitas pelanggan (Y2).

Untuk memeriksa validitas model, terdapat indikator untuk melakukan pemeriksaan, yaitu koefisien determinasi total hasilnya sebagai berikut.

$\mathrm{R}_{\mathrm{m}}^{2}=1-\left(\mathrm{Pe}_{1}\right)^{2}\left(\mathrm{Pe}_{2}\right)^{2}$

$\mathrm{R}_{\mathrm{m}}^{2}=1-(0,782)^{2}(0,585)^{2}$

$\mathrm{R}_{\mathrm{m}}^{2}=0,791$

Keterangan :

$\mathrm{R}_{\mathrm{m}}^{2} \quad$ : Koefisien determinasi total

$\mathrm{e}_{1}, \mathrm{e}_{2}$ : Nilai kekeliruan taksiran standar

Berdasarkan hasil perhitungan koefisien determinasi total, maka diperoleh bahwa keragaman data yang dapat dijelaskan oleh model adalah sebesar 79,1 
persen atau dengan kata lain informasi yang terkandung dalam data sebesar 79,1 persen dapat dijelaskan oleh model sedangkan sisanya 20,9 persen dijelaskan oleh variabel lain yang tidak terdapat dalam model.

1) Pengaruh langsung Kualitas Produk terhadap Brand Image. Rumusan Hipotesis:

$\mathrm{H}_{0}$ : Kualitas Produk tidak berpengaruh positif dan signifikan terhadap Brand Image.

$\mathrm{H}_{1}$ : Kualitas Produk berpengaruh positif dan signifikan terhadap Brand Image.

Taraf nyata 5\% tingkat keyakinan 95\% $(\alpha=0,05)$. Apabila nilai probabilitas lebih besar dari nilai $\alpha=0,05(\mathrm{p}>0,05)$ maka Ho diterima dan H1 ditolak. Apabila nilai probabilitas lebih kecil atau sama dengan nilai $\alpha=0,05(\mathrm{p}<0,05)$, maka $\mathrm{H}_{0}$ ditolak dan $\mathrm{H}_{1}$ diterima. Berdasarkan perhitungan dengan menggunakan program SPSS diperoleh nilai Standardized coefficient beta sebesar 0,624 dan nilai probabilitas sebesar 0,000 . Nilai probabilitas sebesar $0,000<0,05$. Hal ini berarti $\mathrm{H}_{0}$ ditolak dan $\mathrm{H}_{1}$ diterima. Dengan demikian kualitas produk berpengaruh positif dan signifikan terhadap brand image. Hubungan positif dan signifikan antara variabel kualitas produk terhadap variabel Brand Image, dengan demikian kualitas produk berpengaruh positif dan signifikan terhadap brand image. Penelitian yang dilakukan oleh Noerchoidah (2013) juga memperoleh hasil bahwa kualitas produk berpengaruh positif dan signifikan terhadap brand image. 
2) Pengaruh langsung Kualitas produk terhadap Loyalitas Pelanggan Rumusan Hipotesis:

$\mathrm{H}_{0}$ : Kualitas produk tidak berpengaruh positif dan signifikan terhadap loyalitas pelanggan

$\mathrm{H}_{1}$ : Kualitas produk berpengaruh positif dan signifikan terhadap loyalitas pelanggan

Taraf nyata 5\% tingkat keyakinan 95\% $(\alpha=0,05)$. Apabila nilai probabilitas lebih besar dari nilai $\alpha=0,05(\mathrm{p}>0,05)$ maka $\mathrm{H}_{0}$ diterima dan $\mathrm{H}_{1}$ ditolak. Apabila nilai probabilitas lebih kecil atau sama dengan nilai $\alpha=0,05(\mathrm{p}<0,05)$, maka $\mathrm{H}_{0}$ ditolak dan $\mathrm{H}_{1}$ diterima. Berdasarkan perhitungan dengan menggunakan program SPSS diperoleh nilai Standardized coefficient beta sebesar 0,425 dan nilai probabilitas sebesar 0,000 . Nilai probabilitas sebesar $0,000<0,05$. Hal ini berarti $\mathrm{H}_{0}$ ditolak dan $\mathrm{H}_{1}$ diterima. Dengan demikian kualitas produk berpengaruh positif dan signifikan terhadap loyalitas pelanggan. Hubungan positif dan signifikan antara variabel kualitas produk terhadap variabel loyalitas pelanggan menyatakan bahwa semakin baik kualitas produk maka loyalitas pelanggan akan terjalin dari waktu ke waktu. Penelitian yang dilakukan Amryyanti et al. (2013) juga menunjukkan hasil bahwa kualitas produk berpengaruh positif pada loyalitas pelanggan .

3) Pengaruh Brand Image terhadap Loyalitas Pelanggan

Rumusan Hipotesis: 
$\mathrm{H}_{0}$ : Brand Image tidak berpengaruh positif dan signifikan terhadap Loyalitas Pelanggan

$\mathrm{H}_{1}$ : Brand Image berpengaruh positif dan signifikan terhadap Loyalitas Pelanggan.

Taraf nyata 5\% tingkat keyakinan 95\% $(\alpha=0,05)$. Apabil nilai probabilitas lebih besar dari nilai $\alpha=0,05(\mathrm{p}>0,05)$ maka $\mathrm{H}_{0}$ diterima dan $\mathrm{H}_{1}$ ditolak. Apabila nilai probabilitas lebih kecil atau sama dengan nilai $\alpha=0,05(\mathrm{p}<$ 0,05), maka $\mathrm{H}_{0}$ ditolak dan $\mathrm{H}_{1}$ diterima. Berdasarkan perhitungan dengan menggunakan program SPSS diperoleh nilai Standardized coefficient beta sebesar 0,475 dan nilai probabilitas sebesar 0,000 . Nilai probabilitas sebesar $0,000<0,05$. Hal ini berarti $\mathrm{H}_{0}$ ditolak dan $\mathrm{H}_{1}$ diterima. Dengan demikian brand image berpengaruh positif dan signifikan terhadap loyalitas pelanggan. Hubungan positif dan signifikan antara variabel brand image terhadap loyalitas pelanggan, hal ini berarti bahwa brand image dapat memberikan kontribusi dalam membentuk loyalitas pelanggan. Semakin baik brand image maka kontribusi dalam loyalitas pelanggan akan mudah tercapai. Hasil penelitian diatas sejalan juga dengan penelitian yang dilakukan oleh Sulibhavi (2017) yang menyatakan bahwa brand image berpengaruh positif dan signifikan terhadap loyalitas pelanggan.

Uji Sobel dirumuskan dengan persamaan berikut:

$$
\begin{aligned}
& \mathrm{a}=0,585 \\
& \mathrm{~b}=0,473 \\
& \mathrm{~S}_{\mathrm{a}}=0,074 \\
& \mathrm{~S}_{\mathrm{b}}=0,076 \\
& \mathrm{~S}_{\mathrm{ab}}=\sqrt{\mathrm{b}^{2} \mathrm{~S}_{\mathrm{a}}{ }^{2}+\mathrm{a}^{2} \mathrm{Sb}^{2}+\mathrm{S}_{\mathrm{a}}{ }^{2} \mathrm{Sb}^{2}}
\end{aligned}
$$




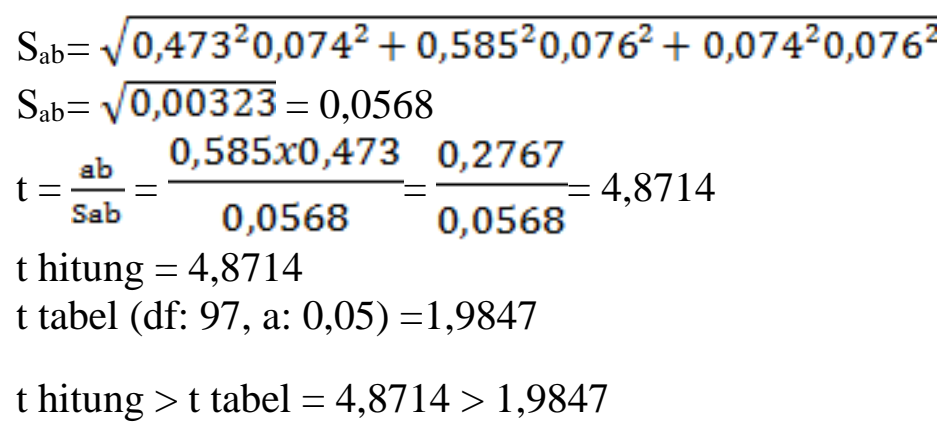

Keterangan :

$\mathrm{S}_{\mathrm{ab}} \quad=$ besarnya standard error tidak langsung

$\mathrm{S}_{\mathrm{a}} \quad=$ standard error koefisien $\mathrm{a}$

$\mathrm{S}_{\mathrm{b}} \quad=$ standard error koefisien $\mathrm{b}$

$\mathrm{a} \quad=$ koefisien jalur $\mathrm{X}$ terhadap $\mathrm{Y} 1$

$\mathrm{b} \quad=$ koefisien jalur Y1 terhadap Y2

$\mathrm{ab}=$ hasil kali koefisien jalur X terhadap koefisien jalur Y1 (a) dengan jalur Y1 terhadap Y2 (b).

Oleh karena Z hitung sebesar 4,8714 > 1,9847 artinya brand image (Y1) sebagai variabel mediasi pengaruh tidak langsung kualitas produk (X) terhadap loyalitas pelanggan (Y2). Variabel brand image sebagai variabel mediasi berpengaruh signifikan secara tidak langsung terhadap loyalitas pelanggan melalui variabel kualitas produk. Dengan demikian hasil ini sejalan dengan penelitian dari Dei dan Sukaatmaja (2015) yang menyatakan bahwa brand image mampu berperan sebagai variabel mediasi.

\section{SIMPULAN DAN SARAN}

Berdasarkan hasil analisis yang telah diuraikan pada bab sebelumnya, maka dapat ditarik simpulan bahwa kualitas produk berpengaruh positif dan signifikan terhadap brand image Kober Mie Setan yang artinya semakin baik kualitas produk maka brand image Kober Mie Setan akan baik dimata konsumen. Kualitas produk berpengaruh positif dan signifikan terhadap loyalitas pelanggan Kober Mie Setan 
yang artinya semakin baik kualitas produk yang ditawarkan maka konsumen akan semakin loyal terhadap Kober Mie Setan. Brand image berpengaruh positif dan signifikan terhadap loyalitas pelanggan Kober Mie Setan yang artinya semakin baik brand image di mata konsumen maka loyalitas pelanggan akan selalu terjaga seiring berjalannya waktu. Brand image mampu memediasi secara signifikan kualitas produk terhadap loyalitas pelanggan yang artinya brand image mampu mempengaruhi kualitas produk terhadap loyalitas pelanggan Kober Mie Setan.

Mengingat sangat pentingnya loyalitas pelanggan, maka perusahaan harus dapat meyakinkan konsumen dengan brand image yang positif seperti menciptakan reputasi yang baik melalui peningkatan kualitas produk, sehingga konsumen akan senantiasa loyal terhadap perusahaan dan mempertahankan konsumen agar tidak berpindah ke pesaing Kober Mie Setan. Bagi peneliti berikutnya, untuk meningkatkan kualitas penelitian sebaiknya memperluas ruang lingkup penelitian dan menambahkan beberapa variabel.

\section{REFERENSI}

Amryyanti, Ruth, I Putu Gde Sukaatmaja, dan Ketut Nurcahya. Pengaruh KualitasLayanan, Produk, Dan Kewajaran Harga Terhadap Kepuasan Dan Loyalitas Pelanggan Pada Lnc Skin Care Singaraja, E-Jurnal Ekonomi dan Bisnis Universitas Udayana Vol. 2 No.1.h.22-29

Chao, Ren-Fang, Tai-Chi Wu, Wei-Ti Yen. 2015. The Influence of Service Quality, Brand Image, and Customer Satisfaction on Customer Loyalty for Private Karaoke Roomsin Taiwan. The Journal of Global Business Management. Vol. 11. No. 1.pp.59-67

Dei, Gusti Ayu Theoria dan I Putu Gde Sukaatmaja. 2015. Peran Brand Image Memediasi Pengaruh Kredibilitas Celebrity Endorser Terhadap Purchase Intention (Studi Pada Produk Kosmetik Etude House Di Kota Denpasar), E-Jurnal Manajemen Unud Vol. 4 No.5.h.1206-1228 
Gill, Manpreet Singh and Jagrook Dawra. 2010. Evaluating Aaker's Sources Of Brand Equity And The Mediating Role Of Brand Image, Journal of Targeting, Measurement and Analysis for Marketing Vol. 18 No.3/4.pp.189-198

Griffin, Jill. 2005. Customer Loyalty : Menumbuhkan dan Mempertahankan Kesetian Pelanggan, Alih Bahasa oleh Dwi Kartini Yahya.Jakarta : Erlangga.

Halim, Peter, Bambang Swasto, Djamhur Hamid, dan M. Riza Firdaus, 2014. The Influence of Product Quality, Brand Image, and Quality of Service to Customer Trust and Implication on Customer Loyalty (Survey on Customer Brand Sharp Electronics Product at the South Kalimantan Province), European Journal of Business and Management Vol.6 No.29.pp 159-166

Irwanty L Situmorang. 2017. Pengaruh Kualitas Produk dan Iklan terhadap Citra Merek dan Keputusan Pembelian Produk Kecantikan Merek Pond's Pada Remaja di Kota Pekanbaru, Jurnal JOM Fekon Vol.4 No.1.h.72-86

Kurniawati, Dewi. Suharyono. Andriani Kusumawati. 2014. Pengaruh Citra Merek dan Kualitas Produk terhadap Kepuasan dan Loyalitas Pelanggan, Jurnal Administrasi Bisnis (JAB) Vol. 14 No.2.h.1-9

Kotler, Phillip and Gary Armstrong. 2016. Marketing an Introducing Prentice Hall twelfth edition”. England : Pearson Education, Inc.

Liao, Kun-His. 2012. The Casual Effects of Service Quality, Brand Image, Customer Satisfaction on Customer Loyalty in the Leisure Resort Enterprise, China- USA Business Review Vol. 11 No.5.pp.631-642

Minar, Demsi dan Anindia Safitri. 2017. Brand Image and Product Quality on Customer Loyalty (Survey in Cekeran Midun). Journal of Trikonomika Vol. 16 No.1.pp.43-50

Noerchoidah. 2013. Analisis Pengaruh Harga, Kualitas Produk dan Iklan terhadap Brand Image dan Keputusan Pembelian Sepeda Motor Merek Kawasaki. Jurnal WIGA, Vol.3 No.1.h.2088-0944.

Pi, Wan - and Huang, Hsieh-Hong, 2011. Effects Of Promotion On Relationship Quality And Customer Loyalty In The Airline Industry : The Relationship 
Marketing Approach, African Journal Of Business Management Vol.5 pp.4403-4414

Purnamasari, Sinta dan Murwatiningsih. 2015. Brand Image Sebagai Mediasi Pengaruh Promosi, Harga Dan Sikap Konsumen Terhadap Keputusan Pembelian Jamu Nyonya Meneer Di Semarang Timur, Management Analysis Journal Vol. 4 No.3.pp.265-272

Pertiwi, Komang Yulia dan Tjok Gde Raka Sukawati. 2017. Brand Image Memediasi WOM terhadap Niat Menggunakan Wedding Service di Cahya Dewi Beauty Salon Denpasar, E-Jurnal Manajemen Unud Vol. 6 No. 5.h.2642-2670

Pratama, I Gst Bgs A. Cahya Diatmika Eka; Ni Nyoman Kerti Yasa dan Nyoman Nurcaya. 2018. The Role of Brand Image in Mediating the Influence of Sponsorship on the Intention to Purchase. International Journal of Management and Commerce Innovation. Vol. 5, Issue 2, pp. 997-1003

Riduwan dan Engkos Achmad Kuncoro. 2011. Cara Menggunakan dan Memakai Path Analysis (analisis jalur). Bandung : Alfabeta.

Sarwono, Jonathan. 2012. Path Analysis, Aplikasi, Prosedur Analisis untuk Riset Skripsi, Tesis, dan Disertasi. Jakarta: PT. Elex Media Komputindo

Saraswati, Agung Ratih dan Ketut Rahyuda. 2017. Brand Image Memediasi Kualitas Produk dan Harga dengan Keputusan Pembelian Smartphone Apple Di Kota Denpasar, E-Jurnal Manajemen Unud Vol. 6 No.6.h.32523282.

Sugiyono. 2013. Metode Penelitian Pendidikan (Pendekatan Kualitatif, Kuantitatif, dan R\&D). Bandung; Alfabeta.

Sulibhavi, Basavaraj and Shivashankar K. 2017. The Impact Of Brand Image On Customer's Loyalty Towards Private Label Brands : The Mediating Effect Of Satisfaction. Hubli-Dharwad Conglomerate City Of Karnataka, International Journal of Marketing \& Financial Management Vol. 5 No. 8.pp.43-50

Tjahjaningsih, Endang. 2013. Pengaruh Citra Dan Promosi Terhadap Kepuasan Pelanggan Serta Dampaknya Terhadap Loyalitas Pelanggan (Studi Pada Pelanggan Supermarket Carrefour Di Semarang). Media Ekonomi Manajemen Vol. 28 No. 2.h.13-27 